\title{
Correction to: Genetic predisposition in children with cancer - affected families' acceptance of Trio-WES
}

\author{
Triantafyllia Brozou ${ }^{1}$ • Julia Taeubner ${ }^{1} \cdot$ Eunike Velleuer $^{1} \cdot$ Martin Dugas $^{2}$. \\ Dagmar Wieczorek $^{3}$ - Arndt Borkhardt ${ }^{1}$ - Michaela Kuhlen ${ }^{1}$ (D)
}

Published online: 6 November 2017

(C) Springer-Verlag GmbH Germany 2017

\section{Correction to: Eur J Pediatr}

https://doi.org/10.1007/s00431-017-2997-6

The original version of this article, unfortunately, contained an error.

The reference citations in the original paper are incorrectly cited to its corresponding bibliographic information.

The original article was corrected.

The online version of the original article can be found at https://doi.org/ 10.1007/s00431-017-2997-6

Michaela Kuhlen

Michaela.Kuhlen@med.uni-duesseldorf.de

Triantafyllia Brozou

Triantafyllia.Brozou@med.uni-duesseldorf.de

Julia Taeubner

Julia.Taeubner@med.uni-duesseldorf.de

Eunike Velleuer

Eunike.Velleuer@med.uni-duesseldorf.de

Martin Dugas

Martin.Dugas@ukmuenster.de

Dagmar Wieczorek

Dagmar.Wieczorek@med.uni-duesseldorf.de
Arndt Borkhardt

Arndt.Borkhardt@med.uni-duesseldorf.de

Department of Pediatric Oncology, Hematology and Clinical Immunology, University Children's Hospital, Medical Faculty, Heinrich Heine University, Moorenstr. 5, 40225 Duesseldorf, Germany

2 Institute of Medical Informatics, University of Muenster, Muenster, Germany

3 Institute of Human Genetics, Medical Faculty, Heinrich Heine University, Duesseldorf, Germany 